\title{
A new inexpensive method for the preparation of acicular precursors for magnetic recording media
}

\author{
M R ANANTHARAMAN*, K V JOSEPH and H V KEER ${ }^{+}$ \\ Department of Physics, Cochin University of Science and Technology, Kochi 682022, India \\ ${ }^{+}$Department of Chemistry, Indian Institute of Technology, Mumbai 400076, India \\ MS received 3 February 1997; revised 3 May 1997

\begin{abstract}
Magnetic materials meant for audio/video recording applications necessitate that polycrystalline materials be in acicular shape. So preparation of acicular precursors for magnetic storage materials assumes significance. The employment of aqueous solutions do not produce needle shape crystallites. Glycerol is one of the complexing media used for the precipitation of ferrous oxalate dihydrate. An inexpensive method using starch for preparation of acicular particles is described. The influence of an additive namely Gd on acicularity is also investigated.
\end{abstract}

Keywords. Magnetic recording media; gamma ferric oxide: acicular particles.

\section{Introduction}

Magnetic materials, especially those meant for audio/video and other recording applications necessitate that the polycrystalline materials be in the acicular shape (needle-shaped crystallites) (Bate 1991). Acicularity in turn determines the signal to noise ratio, since needle-shaped particles can give rise to higher coercive force and better alignment of particles, which in turn produce less noise during recording (Deng et al 1992). The topotactic decomposition of acicular precursors results in acicular particles with the required size and shape. Hence preparation of precursors in the acicular form is a prerequisite for the synthesis of potential materials for magnetic recording applications.

It has been found that the preparation of precursors in aqueous medium by coprecipitation techniques results in spherical particles (Anantharaman 1984). One of the methods for the precipitation of needle-shaped particles is the employment of a complexing medium instead of a simple salt aqueous medium. Glycerol, starch solution and polyvinylalcohol (PVA) are some examples of complexing media.

In this communication we present a simple technique using an inexpensive medium of starch solution for the precipitation of oxalate precursors in the acicular shape. Details regarding the preparative conditions are cited here. The influence of an additive like gadolinium on acicularity is also investigated.

\section{Experimental}

Deffeyer and Tyler (1975) reported that acicular metal carboxylates can be prepared by precipitating them from a solution containing glycerol. Seshan et al (1981) reported the synthesis of acicular ferrous oxalate dihydrate (FOD) in a glycerol medium. Since glycerol is an expensive medium for commercial use, a search for a cheaper medium was

* Author for correspondence 
natural. So it was thought worthwhile to carry out the preparation of FOD in other complexing media like PVA or starch. For the preparation of acicular FOD the method employed by Brown and Bevan (1966) was modified. Equal volumes of complexing medium and water were employed as the precipitating medium. Ten percent starch solution was prepared by adding $10 \mathrm{~g}$ of soluble starch into $100 \mathrm{cc}$ of hot water. The resultant solution was heated and stirred well till it became transparent. Around $25 \mathrm{~g}$ of anhydrous ferrous sulphate was dissolved in a mixture of $75 \mathrm{cc}$ of starch solution. The solution was heated to the required temperature. The resultant solution was magnetically stirred. To this solution $25 \mathrm{~g}$ of oxalic acid and $200 \mathrm{cc}$ each of starch solution and water were added with constant stirring. The addition of oxalic acid was dropwise to facilitate the formation of fine uniform acicular particles of ferrous oxalate dihydrate (FOD). These particles were filtered off and washed with hot water and dried in a hot air oven at $373 \mathrm{~K}$. The same procedure was repeated for the preparation of FOD using PVA and glycerol. Various samples were prepared at different precipitation temperatures and concentrations. To study the effect of additives on the acicularity of polycrystals in complexing media, a set of samples were prepared with Gd as an additive. Gd was used as an additive to investigate its effect as a dopant on modifying the magnetic properties of $\gamma-\mathrm{Fe}_{2} \mathrm{O}_{3}$. Any effect of the additive on the shape of precursors will also have its effect on acicularity. FOD containing 1,2, 4, 6, 8, 10 and 16 at. $\%$ of $\mathrm{Gd}$ were prepared using starch as the complexing medium, by the method of co-precipitation technique using the required amount of gadolinium sulphate, ferrous sulphate and oxalic acid.

\section{Results}

Aqueous medium was found to be nonconducive for the precipitation of acicular polycrystalline materials. The employment of polyvinyl alcohol also did not yield needle shaped FOD crystallites. The role of different complexing media on the formation of acicular particles was investigated for several complexing agents. The results are given in table 1 . As it is evident from table 1 , good uniform acicular particles could be prepared by employing starch solution as a complexing medium.

Table 1. Role of different complexing media and aqueous solution on the formation of acicular particles.

\begin{tabular}{lccccc}
\hline Medium used & $\begin{array}{c}\text { Temp. } \\
\text { condition }\end{array}$ & $\begin{array}{c}\text { Particle } \\
\text { shape }\end{array}$ & $\begin{array}{c}\text { Average } \\
\text { particle length } \\
(\mu \mathrm{m})\end{array}$ & $\begin{array}{c}\text { Average } \\
\text { particle breadth } \\
(\mu \mathrm{m})\end{array}$ & $\begin{array}{c}\text { Length/ } \\
\text { breadth } \\
\text { ratio }\end{array}$ \\
\hline Polyvinyl alcohol & $60^{\circ} \mathrm{C}$ & Spherical & 17.05 & & \\
Aqueous solution & $60^{\circ} \mathrm{C}$ & Spherical & 92.8 & & \\
Glycerol & $60^{\circ} \mathrm{C}$ & Acicular & 30.0 & 18.0 & 1.7 \\
Starch & $60^{\circ} \mathrm{C}$ & Acicular & 57.58 & 28.03 & $2 \cdot 0$ \\
Starch & $55^{\circ} \mathrm{C}$ & Acicular & 48.49 & 6.82 & 7.11 \\
Starch & $65^{\circ} \mathrm{C}$ & Acicular & 22.73 & 13.83 & 1.64 \\
Starch & $75^{\circ} \mathrm{C}$ & Spherical & 26.52 & & \\
Starch & $85^{\circ} \mathrm{C}$ & Spherical & 37.88 & & \\
\hline
\end{tabular}

Concentration of the medium: $10 \%$ 
Table 2. Effect of gadolinium as an additive on ferrous oxalate dihydrate on the acicularity and particle size for various concentrations.

\begin{tabular}{lcccc}
\hline $\begin{array}{l}\text { Percentage of } \\
\text { Gd added } \\
\text { atomic\% } \%\end{array}$ & $\begin{array}{c}\text { Average } \\
\text { Particle } \\
\text { shape }\end{array}$ & $\begin{array}{c}\text { particle length } \\
(\mu \mathrm{m})\end{array}$ & $\begin{array}{c}\text { Average } \\
\text { particle breadth } \\
(\mu \mathrm{m})\end{array}$ & $\begin{array}{c}\text { Length/ } \\
\text { breadth } \\
\text { ratio }\end{array}$ \\
\hline 1 & Acicular & 34 & 17 & $2 \cdot 00$ \\
2 & Acicular & 42 & 20 & $2 \cdot 10$ \\
4 & Acicular & 47 & 19 & $2 \cdot 47$ \\
6 & Acicular & 50 & 21 & $2 \cdot 40$ \\
8 & Acicular & 26 & 14 & $1 \cdot 90$ \\
10 & Not acicular & 53 & & \\
16 & Spherical & 63 & & \\
\hline
\end{tabular}

Precipitation was at $60 \mathrm{C}$ with $10 \%$ starch solution
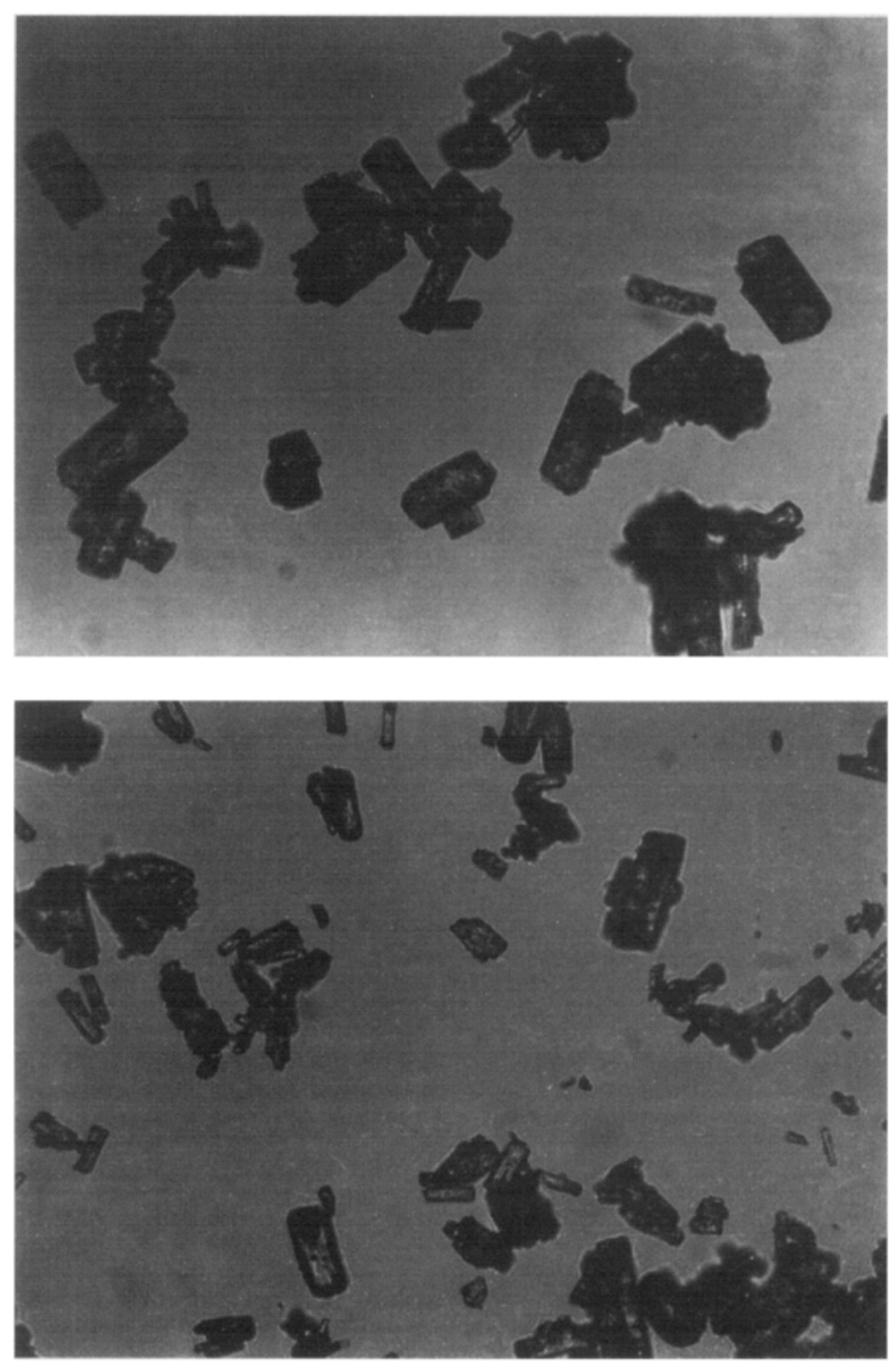

Figure 1. Optical micrograph depicting acicular particles of ferrous oxalate dinydrate prepared using a complexing medium of starch. 

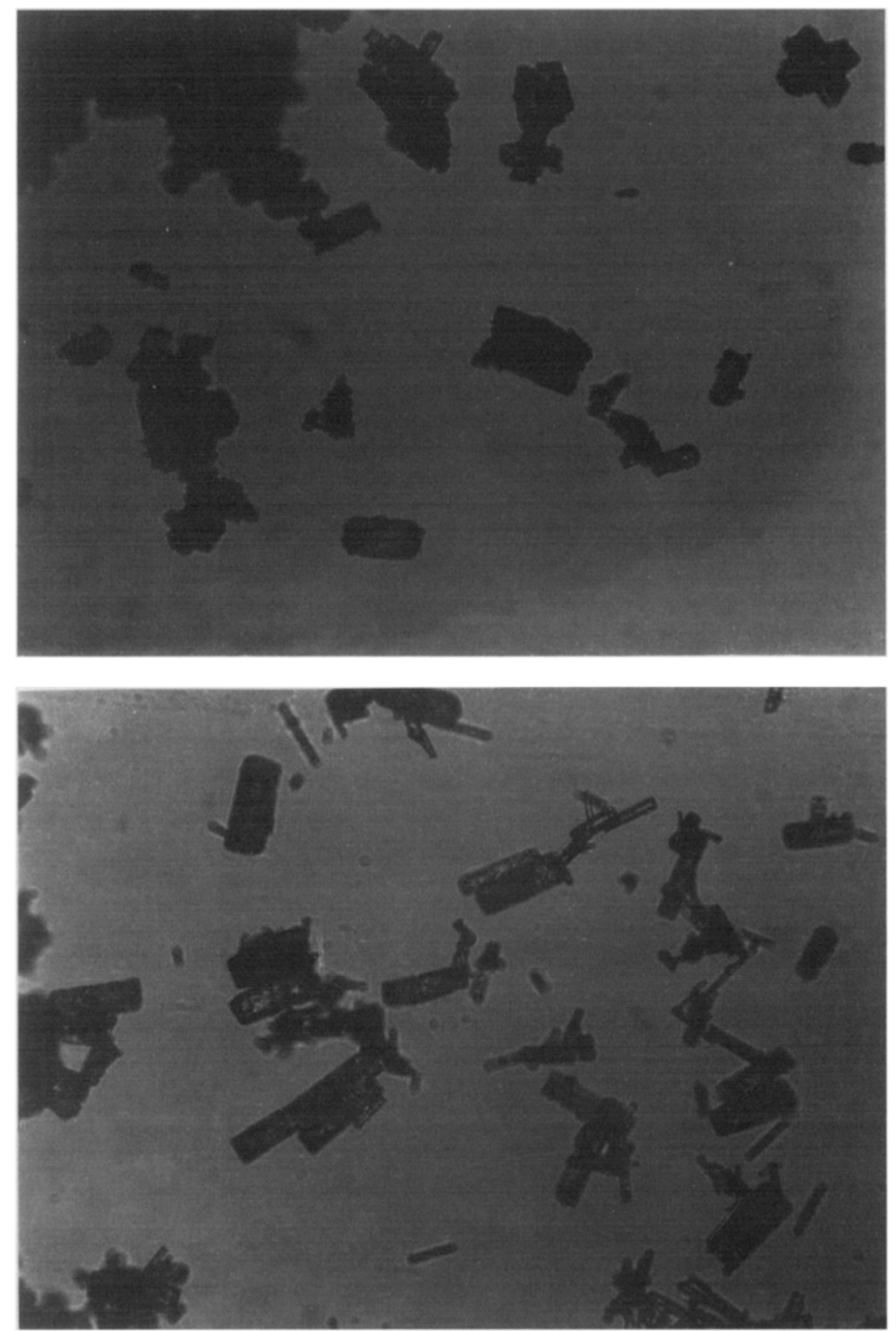

Figure 2. Optical micrograph showing acicular ferrous oxalate dihydrate containing 2 and $4 \%$ of gadolinium.

The effect of temperature on the formation of acicular crystallites, was investigated (table 2). It can be seen that good acicular crystallites could be prepared with $10 \%$ concentration of starch at $338 \mathrm{~K}$. Beyond an optimum concentration of $10 \%$ starch, the particles are found to be spherical in nature. The above findings are further substantiated by figure 1 taken using optical microscope (Versamet 2). Table 2 shows details 


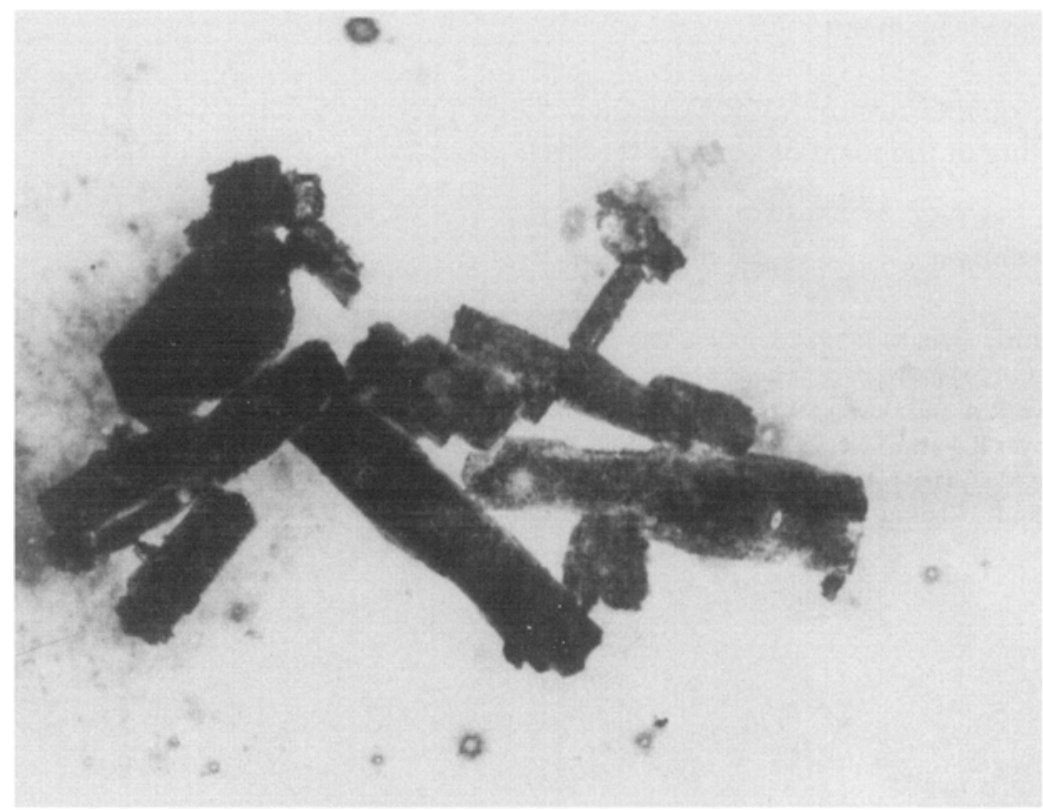

Figure 3. Transmission clectron micrograph of $\dddot{i}_{-}-\mathrm{Fc}_{2} \mathrm{O}_{3}$ synthesized using the acicular precursors prepared with starch as the complexing medium.

regarding the effect of $\mathrm{Gd}$ on particle size and shape. It can be seen from this table that for concentrations up to $8 \mathrm{at} \%$ of Gd the acicularity remained intact. At higher concentrations a deterioration in the acicularity of particles is noted. The micrographs depicting the effect of $\mathrm{Gd}$ are shown in figure 2. Finally, these acicular particles were then decomposed into $;-\mathrm{Fe}_{2} \mathrm{O}_{3}$. The $\mathrm{X}$-ray diffraction data along with magnetization measurements confirms the formation of $\gamma-\mathrm{Fe}_{2} \mathrm{O}_{3}$. The TEM micrograph taken using TEM (Philips EM 301) of $;-\mathrm{Fe}_{2} \mathrm{O}_{3}$ are shown in figure 3 . These confirm the formation of needle-shaped particles from acicular precursors.

\section{Conclusion}

Pure FOD prepared from ferrous sulphate and oxalic acid in an aqueous medium resulted only in spherical particles. The presence of a complexing medium like starch solution during co-precipitation, aided in the formation of acicular particles of FOD which had uniform size and shape. The optimum concentration and optimum temperature were 10 and $330 \mathrm{~K}$ respectively. The present work suggests that additives like Gd have a decisive role in determining the size, and shape of the particles. At higher concentrations of the additives, there is a tendency to revert to sphericity accompanied by large reduction in particle size. The technique of employing complexing medium can be suitably modified for the preparation of other precursors by the method of co-precipitation. The role of complexing medium in the precipitation of acicular crystallites is being investigated separately from a fundamental point of view. 


\section{Acknowledgement}

One of the authors (MRA) thanks the University Grants Commission (UGC) for funding in the form of a minor research programme.

\section{References}

Anantharaman M R 1984 Synthesis and properties of spinel like ferrites, Ph. D. Thesis, IIT Bombay Bate G 1991 J. Magn. \& Magn. Mater. 100413

Brown R A and Bevan S C 1966 J. Inorg. Nucl. Chem. 28367

Deffeyer R J and Tyler W R 1975 Chemical Abstracts $8318752 \mathrm{~b}$

Deng M C. Hsu S L and Chin T S 1992 IEEE Trans. Magn. 282385

Seshan K, Chakrabarty D K and Biswas A B 1981 Phys. Status Solidi (a)63 K123 